\title{
Estimulação da consciência fonológica na Síndrome de Down
}

\author{
Phonological awareness training in Down Syndrome \\ Maria Eugênia da Fontoura Porcellis \\ Universidade Federal do Pampa, Bagé, RS, Brasil \\ Aline Lorandi \\ Universidade do Vale do Rio dos Sinos, São Leopoldo, RS, Brasil \\ Melina Lorandi \\ Universidade Federal do Rio Grande do Sul, Porto Alegre, RS, Brasil
}

$$
\diamond
$$

Resumo: O presente estudo objetivou avaliar e estimular a consciência fonológica em indivíduos com síndrome de Down. Os 24 participantes, divididos em três grupos, foram testados em suas habilidades de consciência fonológica e, em seguida, os grupos experimentais (um com desenvolvimento típico e um com síndrome de Down) realizaram um programa de estimulação dessas habilidades que teve a duração de seis semanas. Como resultado, os dois grupos experimentais foram significativamente melhores no pós teste, devido à eficiência da estimulação, e apresentaram melhor desempenho que o grupo controle (sem a síndrome). Além disso, o grupo com síndrome de Down, após a estimulação, obteve um aprimoramento superior que o grupo experimental sem a síndrome, provavelmente por terem realizado as atividades individualmente. Destaca-se o fato de que as atividades de estimulação foram especialmente desenvolvidas em função das dificuldades de memória, de atenção e de linguagem expressiva normalmente vinculadas à síndrome. Algumas reflexões sobre opções metodológicas são sugeridas em relação à avaliação e ao ensino de populações atípicas.

Palavras-chave: Desenvolvimento atípico; Desenvolvimento da linguagem; Consciência linguística

\begin{abstract}
The present study aimed at evaluating and training phonological awareness in Down syndrome. The 24 participants, divided in three groups, were assessed in their metaphonological abilities and then the experimental groups (one of them typically developing and the other one with Down syndrome) went through a six-week program to train such abilities. As a result, the two experimental groups were significantly better in the post-test, due to the training program efficacy, and presented a better performance than the control group in the post-test. Furthermore, the Down syndrome group, after training, had an even better improvement than the typically developing group, probably because the training sections delivered for them were in an individual basis. We highlight the fact that all of the training activities were especially designed taking into account the difficulties related to memory, attention and expressive language, usually linked to this syndrome. Some points are made regarding methodological and teaching issues in assessing atypical populations.
\end{abstract}

Keywords: Atypical development; Language development; Linguistic awareness 


\section{Introdução}

A consciência fonológica tem sido objeto de intensa investigação em virtude de descobertas realizadas na década de 1980 (BRADLEY; BRYANT, 1983, MORAIS et al., 1986) e do início da de 1990 (GOSWAMI; BRYANT, 1990), as quais apontam que habilidades de lidar com fonemas poderia predizer o sucesso na alfabetização. A estreita ligação entre consciência fonológica e alfabetização no desenvolvimento típico ganhou espaço, no decorrer das últimas décadas, nas investigações das áreas da Educação, da Linguística, da Fonoaudiologia e da Psicologia, sendo investigada atualmente nos laboratórios de Neurociência.

Contudo, a consciência fonológica na síndrome de Down (doravante SD) recebeu menos atenção. Embora haja um considerável número de pesquisas sobre essa temática (COSSU et al., 1993; CUPPLES; IACONO, 2000; CARDOSO-MARTINS; FRITH, 2001; FLETCHER; BUCKLEY, 2002, LAWS; GUNS, 2002; SNOWLING; SULME; MERCER, 2002; CARDOSOMARTINS; MICHALICK; POLLO, 2002; KENNEDY; FLYNN, 2003ab; ROCH; JARROLD, 2008; BAYLLIS; SNOWLING, 2012; HULME et al., 2012; LORANDI, no prelo), os resultados são inquietantes, uma vez que não há um consenso sobre: se há níveis mensuráveis de consciência fonológica na $\mathrm{SD}$, se o sucesso na escrita e na leitura depende dessa habilidade e se é possível estimulá-la com eficácia ${ }^{1}$.

Tendo em vista complementar a discussão sobre o assunto, apresenta-se uma pesquisa voltada à avaliação e à estimulação da consciência fonológica em indivíduos com SD e à comparação dos resultados com um grupo controle e um experimental de crianças em fase préescolar. Adicionalmente, a reflexão proposta dedica-se a oferecer subsídios para que se repensem as formas de se avaliar e estimular a habilidade de lidar com os sons da língua para populações com desenvolvimento atípico. Também estendemos a reflexão para aspectos ligados ao ensino e à aprendizagem, de modo que levem em consideração necessidades particulares em função de dificuldades cognitivas e linguísticas.

\section{Síndrome de Down}

A síndrome de Down é caracterizada como uma alteração cromossômica, mais especificamente, do cromossomo 21, sendo que a maioria dos casos resulta em trissomia. Essa trissomia é responsável por déficits no desenvolvimento neurológico, tanto nas capacidades

Para uma revisão de trabalhos sobre consciência fonológica e SD, sugere-se a leitura de Lorandi (no prelo). neuropsicomotoras quanto nas habilidades cognitivas (SCHWARTZMAN, 1999).

Os déficits resultantes da alteração cromossômica e da forma como os sujeitos que apresentam a síndrome interagem com seu ambiente impactam também a linguagem. Assim, indivíduos com síndrome de Down apresentam deficiências na linguagem expressiva, principalmente com relação à inteligibilidade de fala, à morfologia e à sintaxe, aliados aos déficits na memória de trabalho fonológica. Apesar desses comprometimentos, os sujeitos com síndrome de Down têm relativas vantagens ligadas à compreensão do léxico em relação à idade mental não verbal (MILLER; LEDDY; LEAVITT, 1999; CHAPMAN; HESKETH, 2000; CHAPMAN, 1999, 2003; ABBEDUTO; CHAPMAN, 2005). Chapman e Hesketh (2001) destacam que o grau de comprometimento varia significativamente de sujeito para sujeito.

Diante do exposto, ressalta-se que os sujeitos com SD apresentam dificuldades na fonologia, desde as primeiras produções (STRAY-GUNDERSEN, 1986), manifestando alguns equívocos relacionados à pronúncia de sons, à supressão de consoantes finais, quando comparadas a crianças menores sem a síndrome (DODD, 1976; ROSIN et al., 1988). Embora o processamento fonológico das crianças com Down desenvolva-se semelhantemente a crianças com desenvolvimento típico, esse processamento dá-se de forma mais lenta (BLEILE; SCHUEEARTZ, 1984; STOEL-GAMMON, 1980). Como já referido, a inteligibilidade de fala é prejudicada nesses sujeitos, porém a causa dessa inteligibilidade não é bem definida, podendo associar-se a equívocos na produção de sons, na segmentação e formação de palavras, à apraxia e/ou à disartria (ROBERTS; PRICE; MALKIN, 2007).

Nessa perspectiva, são necessárias mais pesquisas para definir como fatores fonológicos, que incluem o nível do som ou o suprassegmetal (velocidade e ritmo); fatores motores (relativos à mobilidade da língua); fatores cognitivos, relativos à memória de trabalho fonológica; ou perda de audição devido a otities médias, comuns nessa população podem ter influência na inteligibilidade de fala desses indivíduos (ROBERTS; PRICE; MALKIN, 2007).

É importante destacar o fato de que todos esses estudos asseguram que os sujeitos com síndrome de Down têm déficits relacionados à memória de trabalho auditiva. Esses déficitis parecem estar subjacentes às dificuldades de linguagem expressiva, sendo estas associadas a diferenças individuais (CHAPMAN; HESKETH, 2001; GATHERCOLE et al., 2004).

Para Chapman (1997), a memória auditiva de curto prazo é um agente para as diferenças individuais apresentadas pelos indivíduos com síndrome de Down. Segundo Chapman e Hesketh (2001), tais déficits relacionados à memória de curto prazo manifestam-se já 
na infância. Esses autores ainda salientam que o fenótipo vinculado à síndrome de Down surge de uma maneira desenvolvimental.

No quadro dos déficits relativos à linguagem, também encontram-se dificuldades ligadas à consciência fonológica, foco deste estudo, sobre a qual serão tecidos alguns comentários.

\subsection{Consciência fonológica}

Entende-se como consciência fonológica, de modo geral, o conhecimento dos sons que constituem as palavras que são pronunciadas e escutadas pelas pessoas (CARDOSO-MARTINS, 1991), assim como a habilidade que possibilita a identificação de rimas, a percepção dos sons que iniciam ou terminam as palavras e a manipulação de fonemas para a formação de novas palavras (CARDOSO-MARTINS, 1991; FREITAS, 2003). Freitas (2004) faz menção de que, desde cedo, as crianças são capazes de separar, oralmente, as sílabas, o que mostra evidências de um nível de consciência fonológica.

Identificam-se, em termos de consciência fonológica, em geral, três níveis linguísticos distintos: um desses níveis faz alusão à consciência da sílaba, que envolve o conhecimento para separar, juntar, transpor e alterar as sílabas das palavras. Outro nível faz referência à consciência das unidades intrassilábicas - rimas e aliterações. Esse nível é percebido como a habilidade para reconhecer que a sílaba é formada por duas unidades distintas: o onset ${ }^{2}$, que consiste no início da sílaba, e a rima $^{3}$, que engloba seu núcleo e seu possível declive. $\mathrm{O}$ último nível remete à consciência do fonema, sendo definido como a habilidade para manipular, separar, juntar transpor e alterar unidades ainda menores que a sílaba os fonemas.

Lorandi (2011a), amparada no Modelo de Redescrição Representacional (KARMILOFF-SMITH 1986, 1992,1994) apresenta uma proposta de análise em níveis da consciência fonológica que ultrapassa a dicotomia implícito-explícito. Esse modelo distingue explicitude e consciência, apresentando um nível implícito, que é procedimental, e três explícitos, sendo que os dois últimos níveis (de quatro) são considerados como sendo de consciência. Dessa maneira, Lorandi (2011b, p. 09) ressalta que há como "evidência do nível implícito produções inicialmente produzidas tal como o input (com limitações fonético-fonológicas), em que não se percebe sensibilidade fonológica". Um exemplo de produção desse nível é a por imitação que a criança pode realizar, a partir

\footnotetext{
É formado por uma ou mais consoantes (SELKIRK, 1982).

3 Refere-se a 'rima' como uma estrutura que compõe a sílaba, junto ao onset. Ela pode coincidir ou não com a 'rima' da palavra, que é a forma como a palavra termina.
}

da fala do adulto, de um segmento de aquisição tardia, como um fonema rótico, sem que necessariamente esse som faça parte do seu sistema fonológico (por exemplo, podemos pedir a uma criança de 2 anos que diga "carro". Ela, por imitação, pode reproduzir o som $/ \mathrm{X} /{ }^{4}$, mas seguir produzindo, de forma espontânea, $/ \mathrm{kau} / \mathrm{ou}$ /kalu/).

Já no Explícito 1, o informante manifesta sensibilidade à unidade fonológica, já que pode segmentar a palavra espontaneamente. É possível verificar exemplos de produção próprias de representações de nível Explícito 1 quando, por exemplo, a criança bate palmas de acordo com as sílabas de uma palavra. No Explícito 2, têm-se as tarefas offline de produção de conhecimento fonológico, como as dos testes de consciência fonológica, que revelam acesso consciente, mas sem relato verbal (LORANDI, 2011a). É comum, nesses testes, a criança ter de manipular unidades fonológicas, sem necessariamente explicar o que está fazendo ou por que o está fazendo. Tal autora, para o Explícito 3, relembra a observação feita por um dos participantes de sua pesquisa (LORANDI, 2011b), em que ele diz que uma faca e mafata $^{5}$ são parecidas. Segundo ele, apenas é necessário mudar o ' $\mathrm{t}$ ' por um 'c'. Nesse exemplo, ele não apenas demonstra o seu conhecimento de maneira consciente, como também consegue explicá-lo.

$\mathrm{Na}$ seção seguinte, alguns aspectos relativos à consciência fonológica na SD serão considerados, a partir de alguns estudos importantes na área.

\subsection{Consciência fonológica na síndrome de Down}

Muitas pesquisas que relacionam consciência fonológica à alfabetização das crianças com síndrome de Down apontam resultados satisfatórios no que tange à aquisição da língua escrita, à oralidade, aos atrasos na fala e na linguagem quando mediados pela consciência fonológica (KENNEDY; FLYNN, 2003a).

Embora as crianças com SD tenham diferentes déficits cognitivos de linguagem, audição, visão, é primordial que desenvolvam as habilidades que permeiam a alfabetização (FOWLER; DOHERTY; BOYNTON, 1995; CUPPLES; IACONO, 2000; FLETCHER; BUCKLEY, 2002). Quando comparadas a outras crianças com desenvolvimento atípico, as crianças com SD possuem um melhor desenvolvimento das habilidades que envolvem a linguagem verbal e escrita, a memória e a audição (MARCELL; COHEN, 1992; CHAPMAN; SEUNG; SCHWARTZ; KAY-RAINING; BIRD, 1998; MILLER; LEDDY; LEAVITT, 1999).

\footnotetext{
4 Fricativa velar desvozeada.

Pseudopalavra criada para os testes da referida pesquisa.
} 
Tendo em vista pesquisas recentes como as salientadas, ressalta-se a importância de ações para o desenvolvimento do processo de alfabetização desses sujeitos. Azevedo, Pinto e Guerra (2012) ressaltam que a consciência fonológica deve ser considerada a principal estratégia para o desenvolvimento da alfabetização, uma vez que é a habilidade metalinguística que possibilita a análise de como o som da palavra se estrutura, sendo imprescindível no processamento fonológico, aliado à memória fonológica e à nomeação imediata.

No que concerne aos sujeitos com SD, existem estudos que mostram que esses sujeitos apresentam níveis mensuráveis de consciência fonológica (PORCELLIS, 2015; PINTO, 2009), embora isso não seja consenso (COSU et al., 1993). Kennedy e Flynn (2003a) ressaltam que algumas pesquisas (MAJOR; BERNHARDT, 1998; GILLON, 2000) mostram que, com a estimulação da consciência fonológica em indivíduos com desenvolvimento atípico, o processo de alfabetização pode apontar bons resultados. Outros estudos são menos favoráveis a essa posição ${ }^{6}$.

Independente dos resultados mais ou menos otimistas em relação à consciência fonológica dos indivíduos com $\mathrm{SD}$, essa habilidade certamente representa um déficit na síndrome, o qual pode ser a razão de insucessos com a alfabetização. Também são conhecidas as dificuldades relativas à memória de trabalho. $\mathrm{O}$ modelo de memória trabalhado nesta pesquisa, de Baddeley e Hitch (1974) e Baddeley (1992, 2000, 2002, 2003), é apresentado a seguir.

\section{Memória de trabalho ${ }^{7}$}

A memória de trabalho, para Baddeley (1992), tem a responsabilidade tanto de armazenar de maneira simultânea quando de processar as informações em um curto período de tempo, podendo esse armazenamento durar poucos minutos ou, até mesmo, alguns segundos. Trata-se de um tipo de memória que não permite o armazenamento e a criação de registros permanentes. Baddeley (2000) também ressalta o fato de essa memória ser um sistema organizado para conservar e manipular a informação de maneira rápida, junto ao compartilhamento de tarefas cognitivas, a saber, o raciocínio, a compreensão e a aprendizagem.

De acordo com o autor (ibid), a memória de trabalho divide-se em quatro elementos que se completam entre si, que são: o executivo central, o buffer episódico, o esboço

\footnotetext{
6 Ver Lorandi (no prelo), para uma revisão desses estudos.

7 Destaca-se que há vários modelos teóricos que explicam a memória de trabalho. Neste artigo, utiliza-se o modelo apresentado por Baddeley e Hitch (1974) e Baddeley (2000, 2002, 2003), visto que, nos estudos relacionados à consciência fonológica e à Síndrome de Down, é o mais utilizado.
}

visuoespacial (ou alça visuoespacial) e a alça fonológica, sendo os dois últimos sistemas subsidiários ao executivo central. Ao modelo original (BADDELEY; HITCH, 1976) foi acrescentado o buffer episódico (BADDELEY, 2000).

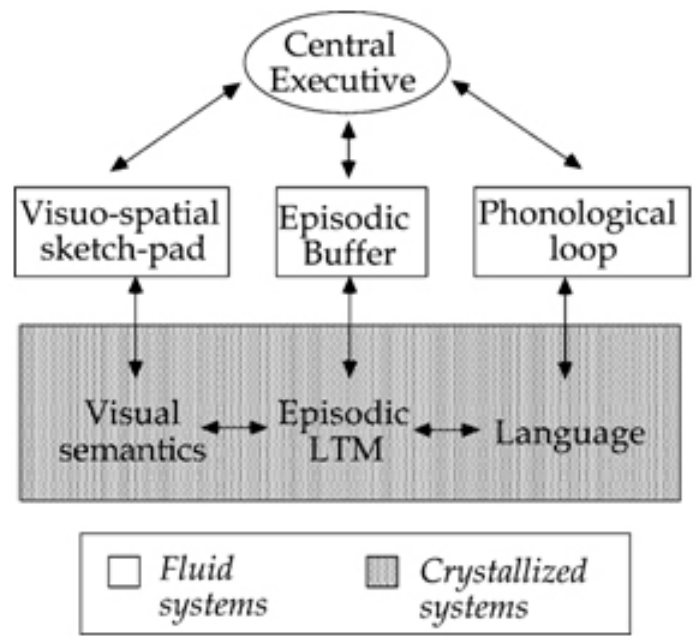

Figura 1. Modelo da memória de trabalho Fonte: Baddeley (2003, p. 196).

A alça fonológica é o componente subsidiário do executivo central considerado importante para questões ligadas à linguagem e, portanto, para fins deste trabalho, é sobre ela que se discorrerá.

"A alça fonológica é provavelmente o mais simples e mais extensivamente investigado componente da memória de trabalho" (BADDELEY, 1992: 558). Esse elemento é um dos focos deste estudo, pois é o responsável em armazenar e analisar as informações trazidas na fala. Desse modo, a alça fonológica é importante não somente para a aquisição da língua materna, como também para a de uma segunda língua (BADDELEY, 2003; BADDELEY et al., 1998). Para Baddeley (2002), esse fato nos leva a perceber a importância dos estudos sobre a alça fonológica para o desenvolvimento da linguagem.

Destaca-se que a alça fonológica é dividida em dois componentes. Tem-se armazenamento fonológico e a repetição subvocal. O primeiro é responsável por guardar rapidamente as informações verbais, que se deterioram rápido, formando representações provisórias dos sons, sendo essencial tanto para o desenvolvimento da fala, quanto para o desenvolvimento fonológico (BADDELEY, 2003). Já o segundo é encarregado de acessar as informações verbais que estão 'escapando', autorizando, assim, a permanência das informações na memória (BADDELEY, 2003), ou seja, a repetição subvocal evita que as informações verbalizadas sejam rapidamente esquecidas (BADDELEY; HITCH, 1974). Em outras palavras, poder-se-ia dizer que, na alça fonológica é possível armazenar e formar representações sonoras 
temporárias, que poderão ser mantidas na memória por meio da subvocalização. Dessa maneira, quanto melhor for o desenvolvimento do armazenamento fonológico, melhor será a capacidade de registro e utilização das informações na comunicação de um sujeito (BADDELEY, 2003). Um exemplo do funcionamento desse mecanismo seria registrar um número de telefone, não pela lembrança visual dos números, mas por sua representação fonológica, repetindo-o até que se consiga digitar o número.

Diante do exposto, percebe-se que "distúrbios na memória de trabalho podem ter impacto sobre os processos de linguagem" (BADDELEY, 2003, p. 196). Assim, déficits na alça fonológica ou nos outros elementos da memória - com menos frequência - podem ocasionar graves danos à aquisição da linguagem. A questão, menos explorada na literatura, é se esses dois componentes tem sempre o mesmo impacto sobre a linguagem ou se agem de modo mais independente. De acordo com esse fato, percebe-se a importância em estudar a memória de trabalho vinculada à linguagem (BADDELEY, 2003).

\section{Metodologia}

\subsection{Participantes}

Este estudo contou com três grupos de 8 participantes cada, sendo dois grupos experimentais e um de controle. $\mathrm{O}$ grupo experimental 1 é o de crianças, adolescentes e adultos com $\mathrm{SD}$, enquanto os dois outros grupos, experimental 2 e de controle, foram formados por crianças sem SD. Como a pesquisa objetivou verificar o efeito da estimulação da consciência fonológica tanto em crianças com quanto nas sem síndrome de Down, o critério para controle dos grupos foi o desempenho na aplicação do CONFIAS $^{8}$ antes da estimulação. Crianças da Pré-escola $1^{9}$ alcançaram um desempenho semelhante aos participantes com SD e, portanto, escolheu-se essa série para grupo experimental e também para controle. O Quadro 1 apresenta informações sobre as idades dos participantes.

Quadro 1. Média e o desvio padrão das idades dos participantes

\begin{tabular}{|l|c|c|}
\hline Grupos & Média & $\begin{array}{c}\text { Desvio } \\
\text { Padrão }\end{array}$ \\
\hline Grupo Experimental com Síndrome de Down & 17,38 & 7,17 \\
\hline Grupo Experimental com Desenvolvimento Típico & 5,38 & 0,52 \\
\hline Grupo Controle com Desenvolvimento Típico & 5,63 & 0,52 \\
\hline
\end{tabular}

Fonte: As autoras.

\footnotetext{
8 Consciência Fonológica: Instrumento de Avaliação Sequencial. O CONFIAS é um instrumento de avaliação de consciência fonológica desenvolvido por psicopedagogas, fonoaudiólogas, linguistas e uma psicóloga (MOOJEN et al., 2003), validado para o português brasileiro.

9 Na escolar em que foram entrevistados os participantes dos grupos experimental sem a síndrome e grupo controle, o nível da "Pré-escola 1" equivale ao penúltimo ano da pré-escola, antes do $1^{\circ}$ ano do Ensino Fundamental.
}

\subsection{Instrumentos}

Para avaliar a consciência fonológica, utilizou-se o CONFIAS, que é um teste validado para o português brasileiro. Conta com 9 tarefas referentes ao nível da sílaba, incluindo o nível intrassilábico, e com 7 referentes ao nível do fonema, em um total de 70 questões. As tarefas incluem junção, segmentação, produção, exclusão e transposição silábica e fonêmica, em graus crescentes de complexidade. Nas primeiras aplicações do teste, verificou-se que os participantes com SD não conseguiam realizar as atividades mais complexas e ficavam frustrados com seu desempenho, perdendo interesse pela sequência do trabalho. Assim, tomou-se a decisão de aplicar apenas as 6 tarefas do nível silábico - síntese (S1), segmentação (S2), Identificação (S3), Identificação de Rima (S4), Produção de rima com sílaba dada (S4) e Produção de rima (S7), além de 3 do nível fonêmico - Produção de palavra com o fonema dado (F1), Identificação de fonema inicial (F2) e Identificação de fonema final (F3). O mesmo critério foi, consequentemente, aplicado aos demais grupos.

Quanto à estimulação da consciência fonológica, foram criados 9 grupos de atividades, que incluíam 6 brincadeiras do nível da sílaba e 3 do nível do fonema, utilizando-se de material concreto, colorido, visando à utilização futura por professores e terapeutas. $\mathrm{O}$ conjunto de atividades deu origem a um produto, nomeado de "Consciência fonológica na síndrome de Down: atividades de estimulação ao desenvolvimento da consciência fonológica em nível de sílaba, rima e fonema - Tutorial para o professor" "10. A aplicação das atividades foi especialmente elaborada para levar em consideração os déficits de memória de trabalho da população com síndrome de Down ${ }^{11}$. As próprias tarefas do CONFIAS serviram de inspiração para a criação de algumas das atividades.

\subsection{Coletas de dados}

As coletas de dados foram realizadas em três etapas: 1) pré aplicação do CONFIAS, com o objetivo de verificar a consciência fonológica em nível de sílaba e em nível de fonema antes da estimulação, 2) estimulação da consciência fonológica e 3) pós aplicação do CONFIAS, para avaliação dos efeitos da estimulação. As etapas 1 e 3 foram realizadas individualmente com cada um dos participantes dos três grupos e somente os grupos experimentais passaram pela etapa 2 , que é a intervenção proposta por este estudo.

\footnotetext{
${ }^{10}$ No produto, há instruções sobre construção do material e sobre sua aplicação.

${ }^{11}$ Há observações também com relação a esses cuidados no material disponível aos professores e terapeutas.
} 
As atividades de estimulação foram realizadas individualmente com o grupo 1 (com SD), dadas as limitações de memória e de atenção que essa população costuma apresentar e também em função de que, embora todos frequentassem a mesma instituição, em virtude das diferenças de idade, as coletas poderiam tornar-se inviáveis. As coletas foram realizadas na instituição que os participantes do grupo com SD frequentavam e também em seus domicílios. O grupo 2 (sem SD), por sua vez, foi composto por 8 crianças de idades muito próximas, da mesma série e da mesma escola e, portanto, optou-se por realizar as atividades em grupo e na escola. $\mathrm{O}$ conjunto de atividades foi desenvolvido durante seis semanas, com um encontro por semana, tendo duração de 60 minutos cada, para os dois grupos experimentais. Todos os participantes tiveram um Termo de Consentimento Livre e Esclarecido assinado por seus pais, assim como cuidados éticos foram observados. Os dados foram analisados estatisticamente.

\section{Resultados}

\subsection{Nível da sílaba}

Os grupos foram comparados em seu desempenho no pré e pós teste. Não houve diferença significativa entre os grupos no pré teste. No pós teste, houve diferença entre os grupos $(p=0,001)$. Comparações a posteriori com o teste post hoc de Bonferroni apontaram diferença significativa entre o grupo controle e os grupos experimentais, sendo $p=0,005$ entre controle e experimental com desenvolvimento típico e $p=0,001$ entre controle e experimental com SD, corroborando para a hipótese de que a intervenção foi eficaz para o nível da sílaba para ambos grupos experimentais. Não houve diferença significativa entre os grupos experimentais $(p=1,000)$.

Para a variável 'nível da sílaba', no pré teste, o desempenho do grupo experimental com $\mathrm{SD}(\mathrm{M}=8,63$; $\mathrm{DP}=4,07)$ foi similar ao grupo controle $(\mathrm{M}=8,63 ; \mathrm{DP}=4,10)$, havendo ficado ambos com desempenho inferior ao grupo experimental com desenvolvimento típico $(\mathrm{M}=12,63$; $\mathrm{DP}=5,99)$. No pós teste, o grupo experimental com $\mathrm{SD}$ $(\mathrm{M}=17,75 ; \mathrm{DP}=4,77)$ superou o escore médio do grupo experimental com desenvolvimento típico $(\mathrm{M}=16,50$; $\mathrm{DP}=4,50$ ), embora essa diferença não seja significativa, ficando ambos com melhor desempenho em relação ao grupo controle $(\mathrm{M}=8,50 ; \mathrm{DP}=4,07)$.

$\mathrm{Na}$ Figura 2, está o desempenho dos grupos no pré teste do nível da sílaba, apontando que o grupo experimental com SD teve um escore parecido com o do grupo controle com desenvolvimento típico. $\mathrm{Na}$ Figura 3, consta o desempenho dos grupos no pós teste para o nível da sílaba, que aponta diferença significativa entre o grupo controle e os grupos experimentais, sendo que o grupo com SD obteve o escore médio mais alto no teste.

Na comparação intragrupo para pré e pós teste, o grupo controle não teve diferença significativa $(p=0,351)$, e os grupos experimentais tiveram diferença significativa. Para o grupo experimental com desenvolvimento típico a análise estatística revelou $p=0,002 \mathrm{e}$, para o grupo experimental com SD, $p=0,001$, apontando que a intervenção foi responsável pela diferença no pré e pós teste, conforme o esperado.
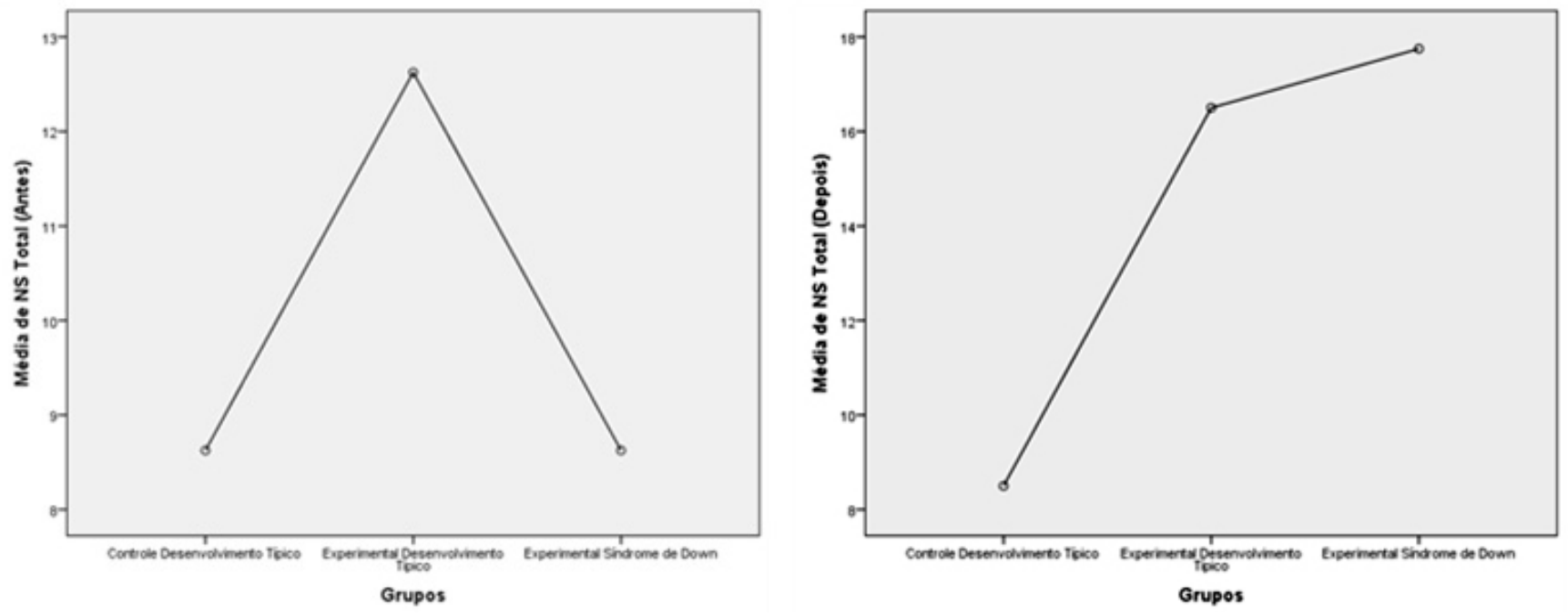

Figuras 2 e 3. Média do nível da sílaba para os grupos experimentais e grupo controle Fonte: As autoras. 


\subsection{Nível do fonema}

Para o nível do fonema, os resultados foram similares aos do nível da sílaba. No pré teste, não houve diferença significativa entre os grupos e, no pós teste, houve diferença significativa. Usando $\mathrm{F}$ de Welch, o resultado da ANOVA 1 fator foi de $F(2,10,479)=5,771 ; p=0,020$. $O$ teste post hoc de Bonferroni indica que só houve diferença significativa entre o grupo controle $(\mathrm{M}=3,75 ; \mathrm{DP}=1,03) \mathrm{e}$ o grupo experimental com $\mathrm{SD}(\mathrm{M}=8,38 ; \mathrm{DP}=4,40)$, sendo $p=0,035$. O grupo experimental com desenvolvimento típico $(\mathrm{M}=6,63 ; \mathrm{DP}=3,62)$ não apresentou diferença significativa quando comparado aos demais grupos no pós teste.

Na Figura 4, encontra-se o resultado do pré teste do nível do fonema para os três grupos, não havendo diferença significativa entre eles. Na Figura 5 está o resultado do pós teste para os grupos, havendo diferença significativa somente entre o grupo controle e o grupo experimental com $\mathrm{SD}(p=0,035)$.

$\mathrm{Na}$ comparação intragrupo entre pré e pós teste, no nível do fonema, assim como no nível da sílaba, o grupo controle não apresentou diferença significativa $(p=0,351)$. O grupo experimental com desenvolvimento típico também não apresentou diferença significativa nesse quesito $(p=0,516)$, o que explica o fato de este não obter diferença significativa em relação aos demais grupos avaliados. Entretanto, o grupo experimental com SD apresentou diferença significativa entre pré e pós teste $(p=0,025)$. Para o nível de fonema, a intervenção foi mais eficaz para os participantes com síndrome de Down.

\subsection{Resultado total}

O resultado total é a soma dos escores obtidos no nível da sílaba e no nível do fonema. Mais uma vez, na comparação entre os grupos no pré teste, não houve diferença significativa, e o resultado para o pós teste foi significativo, sendo $\mathrm{F}(2,21)=9,867$ e $p=0,001$. No teste post hoc de Bonferroni, houve diferença significativa entre o grupo controle $(\mathrm{M}=11,13 ; \mathrm{DP}=4,02)$ e experimental com desenvolvimento típico $(\mathrm{M}=23,13$; $\mathrm{DP}=7,36$ ), sendo $\mathrm{p}=0,009$, e do controle para o grupo experimental com síndrome de Down $(\mathrm{M}=26,23$; $\mathrm{DP}=9,11)$, com $p=0,001$.

Na Figura 6, está o resultado do pré teste, levando em consideração o resultado total para os três grupos, não havendo diferença significativa entre eles. Na Figura 7 está o resultado do pós teste para os grupos, havendo diferença significativa entre o grupo controle e o grupo experimental com SD $(p=0,001)$ e entre o grupo controle e o grupo experimental com desenvolvimento típico $(p=0,009)$.

$\mathrm{Na}$ comparação entre pré teste e pós teste intragrupo para o resultado total, mais uma vez o grupo controle não teve resultados significativos, evidenciando que a falta da intervenção manteve os resultados estáveis para este grupo. Como esperado, os grupos experimentais tiveram resultados significativos, evidenciando que o grupo com desenvolvimento típico $(p=0,025)$ e o grupo com $\mathrm{SD}(p=0,001)$ foram beneficiados em seu resultado pela intervenção proposta pelo estudo.
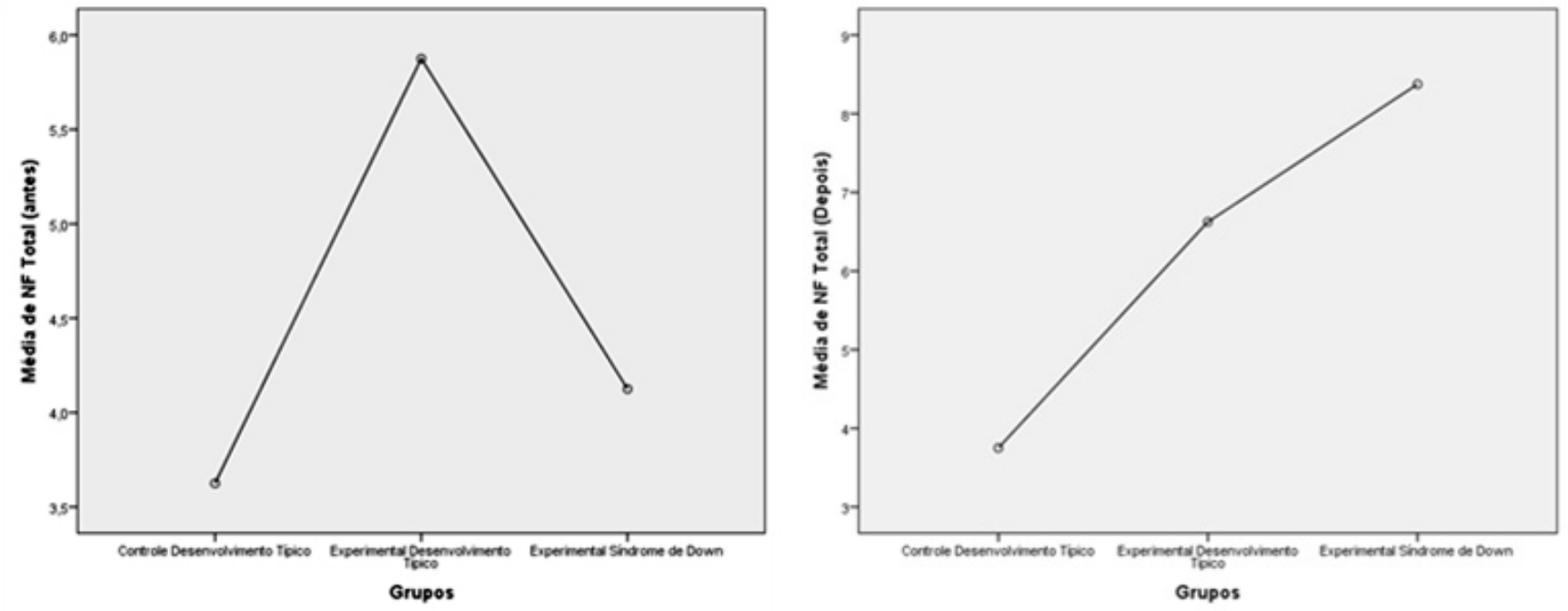

Figuras 4 e 5. Média do nível do fonema para os grupos experimentais e grupo controle Fonte: As autoras. 

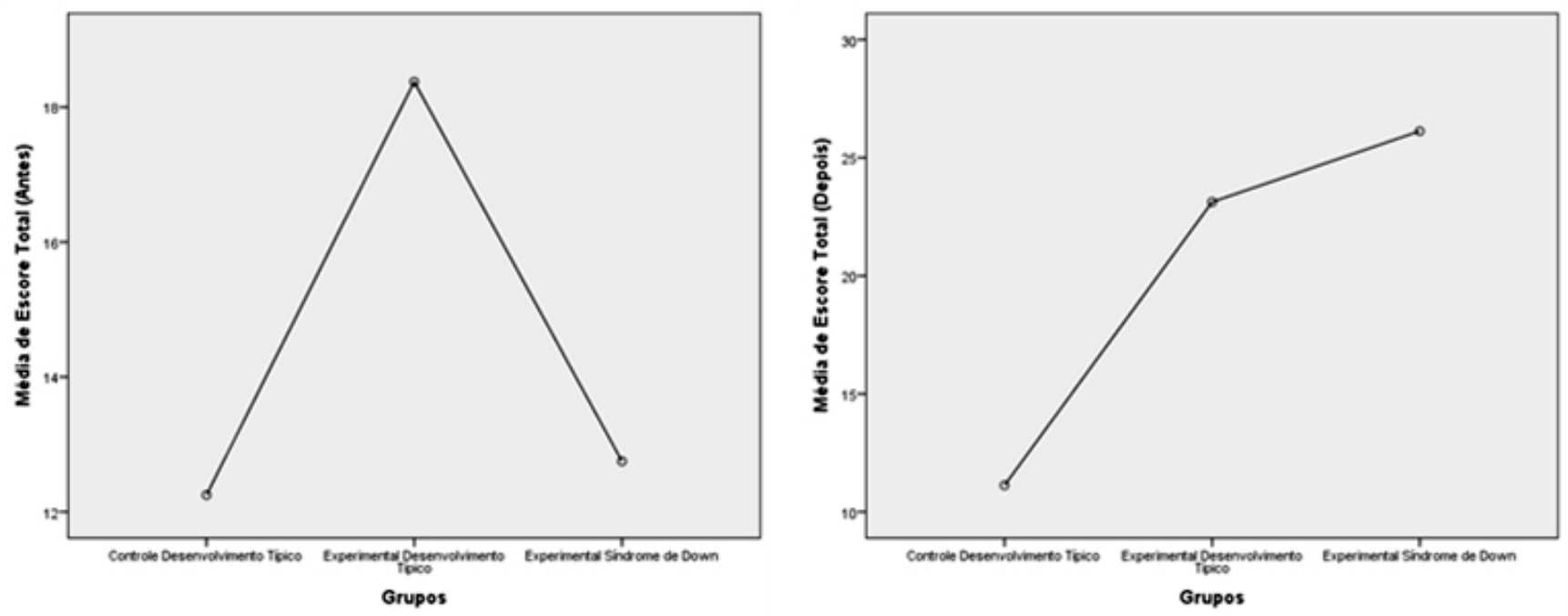

Figuras 6 e 7. Média do escore total para os grupos experimentais e grupo controle Fonte: as autoras.

\section{Análise e discussão dos dados}

O principal objetivo deste trabalho foi verificar a eficácia da elaboração de atividades de estimulação da consciência fonológica especialmente voltadas à população com síndrome de Down, em função de algumas especificidades cognitivas, como os déficits de memória de trabalho e de linguagem de modo geral. Este estudo foi pensado e executado de modo a ajudar a compor um quadro de pesquisas bastante raro, que tem se dedicado a estudar se as crianças, adolescentes e, até mesmo, adultos podem beneficiar-se de programas de intervenção para aprimoramento de sua consciência fonológica.

As atividades foram pensadas de modo a envolver os participantes, que puderam manipular materiais concretos, atraentes visualmente, baseados em palavras concretas (e não abstratas). Também a forma como a aplicação foi realizada previu repetições, de modo a reforçar as informações em sua memória de trabalho.

$\mathrm{O}$ resultado alcançado mostrou que os dois grupos experimentais - com e sem síndrome de Down progrediram em suas habilidades. O grupo controle manteve-se praticamente com o mesmo número de acertos, tanto em nível de sílaba quanto de fonema, na pré e na pós aplicação do CONFIAS. Esse resultado pode ser atribuído ao fato de que as atividades de estimulação da consciência fonológica alcançaram êxito em seu propósito. Acredita-se que as atividades foram eficazes por terem sido elaboradas em função das especificidades cognitivas da população alvo do trabalho.

Estatisticamente, o grupo com síndrome de Down parece ter sido mais beneficiado com a estimulação que o grupo sem a síndrome, o que pode ser explicado em função de que as aplicações, para o grupo com SD, foram feitas individualmente. Esse resultado é bastante motivador, uma vez que leva a pensar que o investimento em atividades individualizadas que promovam o vínculo com os participantes, bem como que levem em consideração suas peculiaridades cognitivas, pode permitir com que avancem no aprimoramento de suas habilidades.

Adicionalmente, destaca-se o fato de que se buscou prover oportunidade para que os participantes demonstrassem suas respostas de modo não verbal, dadas suas dificuldades relativas à linguagem expressiva, possibilitando que apontassem para a figura que representasse a resposta correta. Considera-se importante o professor também explorar formas variadas de averiguar a aprendizagem de seus alunos com SD, utilizando-se de opções como as que foram pensadas nas atividades apresentadas neste estudo. Entende-se que a principal questão é oportunizar o acesso ao que o aluno/ participante pode mostrar, e não tomar como instrumento de avaliação apenas o que já é utilizado para a população de desenvolvimento típico.

Outro ponto importante revelado por esta pesquisa é que os participantes com SD alcançaram êxito no aprimoramento de sua consciência fonológica não só em nível de sílaba, o que é corroborado também por outros estudos (como os de KENNEDY; FLYNN, 2003a; KENNEDY; FLYNN, 2003b; VAN BYSTERVELDTA; GILLONA; MORAN, 2006), mas também em nível de rima e de fonema, conforme escores no pós teste. Essa melhora conduz a reflexões tocantes a, pelo menos, dois aspectos: a metodologia utilizada para avaliação de consciência fonológica nos estudos em geral e a forma como as estimulações são conduzidas nos diferentes estudos. 
A divergência entre os achados dos diferentes estudos parece apontar para o fato de que as diferentes metodologias utilizadas podem ser um dos fatores responsáveis por isso. Para que se possam fazer generalizações sobre o impacto das estimulações das habilidades, uma maior homogeneidade de métodos poderia ser uma solução. Além disso, muitas pesquisas utilizam material pensado para populações de desenvolvimento típico. Essa discussão sugere que se pensem em metodologias para coleta de dados e para estimulação/intervenção que realmente sejam eficazes para que os indivíduos com SD revelem seu conhecimento. É claro que o recorte de participantes, de modo especial em relação à idade, é outro fator a ser considerado. Todavia, o que se quer enfocar com essas observações é a necessidade de se pensarem formas de avaliação dos indivíduos com SD, de modo que procurem levar em consideração seus esforços mediante as habilidades que eles podem demonstrar.

\section{Considerações finais}

O estudo apresentado teve como principal objetivo desenvolver uma metodologia para estimulação da consciência fonológica que tomasse os aspectos cognitivos que comumente são registrados na literatura como sendo alvo de déficits na síndrome de Down, como a memória de trabalho, a atenção e a dificuldade para apreender substantivos abstratos, a fim de adaptá-los, de modo a verificar a consciência fonológica, sem a demanda tão grande dessas habilidades relacionadas. Os resultados sugerem que a adaptação, bem como os materiais em si, foram capazes de promover a estimulação da consciência fonológica nos indivíduos com síndrome de Down em todos os níveis fonológicos avaliados: sílaba, rima e fonema. Embora os resultados para a sílaba tenham sido mais proeminentes, destacam-se os ganhos em nível de fonema e, principalmente, de rima, por serem relatados na literatura como muito difíceis para as pessoas com a síndrome.

A pesquisa com populações de desenvolvimento atípico nos revelam muito sobre o desenvolvimento em si, conforme já apontava Karmiloff-Smith (1998). A coleta de dados, frente a frente com o participante, permite perceber suas necessidades, suas dificuldades e potencialidades. Também permite que o pesquisador perceba melhor sua metodologia, suas limitações e seu alcance. A conclusão inevitável é de que o aprimoramento metodológico é urgente, para que se possa entender como funciona a cognição desses indivíduos.

Também parece importante que o pesquisador seja sensível a ponto de estabelecer um vínculo com seu participante, propiciando que ele se sinta à vontade para responder a atividades e que enxergue possibilidades de adaptar sua metodologia para melhor captar as sutilezas das diferenças individuais observadas, de modo que realmente possa dizer algo sobre o que seu participante tem de conhecimento naquela área específica, e não só o que tem de dificuldades. É fundamental um olhar para o desenvolvimento atípico que contemple a forma como cada síndrome ou transtorno pode responder, revelando seu efetivo potencial. E, acima de tudo, é crucial que o pesquisador entenda o que verdadeiramente está avaliando, buscando não sobrecarregar seu participante com demandas de memória de trabalho e de atenção, por exemplo, quando seu foco são habilidades linguísticas.

Igualmente importante seria estender essa reflexão para o ensino e a aprendizagem. Da concepção de língua e linguagem aos conteúdos a serem ensinados e avaliados, entende-se que, se o professor não investir no potencial de todos os indivíduos com que trabalha, de modo a adaptarse a suas necessidades cognitivas específicas, e na sua formação para seguir informando-se sobre as melhores formas de promover a aprendizagem a todos, a inclusão constituir-se-á ilusória, o que levará pais e os próprios professores à frustração: estes por não conseguirem captar o conhecimento de seus alunos e aqueles por não conseguirem ver na escola um espaço para que seus filhos desenvolvam-se plenamente.

Para finalizar, cabe destacar o papel do professor frente ao investimento no aluno com síndrome de Down e na adaptação de suas avaliações, visando a alcançar sua aprendizagem no escopo do que eles podem manifestar. A reflexão possibilitada pelos resultados desta pesquisa mostram que, adaptando materiais e instrumentos de avaliação, é possível alcançar o conhecimento dos indivíduos com SD e aprimorá-lo. Entende-se que é papel do professor - de todas as áreas - seguir pensando em estratégias para alcançar seu objetivo maior, que é a aprendizagem, para todos os seus alunos, independentemente de suas condições cognitivas. No momento em que o professor atribui o fracasso da aprendizagem a fatores externos, sem ter tentado qualificar suas práticas por meio de conhecimentos adquiridos, inclusive, por meio da pesquisa na área, está delegando suas atribuições ao que não pode controlar. É o professor, em sala de aula e na relação com seus alunos, que pode e deve construir ambientes que potencializem a aprendizagem de todos.

\section{Referências}

ABBEDUTO, L.; CHAPMAN, R. S. Language and communication skills in children with Down syndrome and Fragile x. In: FLETCHER, P.; MILLER, J. (Eds.). Trends in language acquisition research: Developmental theory and language disorders. Amsterdam, NL: John Benjamins, 2005, v. 4, 217 p. 
BADDELEY, A. D. The episodic buffer: A new component of working memory? Trends in Cognitive Sciences, v. 4, p. 417-423, 2000.

BADDELEY, A. D. Working Memory. Science, v. 255, p. 556$559,1992$.

BADDELEY, A. D. Working memory and language: an overview. Journal of Communication Disorders, Bristol, n. 36, p. 189-208, 2003.

BADDELEY, A. D. Fractionating the central executive. In: STUSS, D.; KNIGHT, R. T. (Ed.). Principles of frontal lobe function. New York: Oxford University Press, 2002. p. 246-260.

BADDELEY, A. D.; HITCH, G. J. Working memory. In: BOWER, G. (Ed.). The psychology of learning and motivation. New York: Academic Press, 1974. p. 47-89.

BADDELEY, A. D.; GATHERCOLE, S. E.; PAPAGNO, C. The phonological loop as a language learning device. Psychological Review, v. 105, p. 158-173, 1998.

BLEILE, K.; SCHWARTZ, I. Three perspectives on the speech of children with Down syndrome. J. Commun. Disord., v. 17, p. 87-94, 1984.

BRADLEY, L.; BRYANT, P. Categorizing sounds and learning to read: a causal connection. Nature, v. 301, p. 419-21, 1983.

CARDOSO-MARTINS, C. A sensibilidade fonológica e a aprendizagem inicial da leitura e da escrita. Cadernos de Pesquisa, São Paulo, v. 76, p. 41-49, fev. 1991.

CHAPMAN, R. S. Desenvolvimento da linguagem em crianças e adolescentes com síndrome de Down. In: FLETCHER, P.; MACWHINNEY, B. (Org.). Compêndio da linguagem da criança. Trad. por: Marcos A.G. Domingues. Porto Alegre: Artes Médicas, 1997. p. 517-33.

CHAPMAN, R. S. Language and cognitive development in children and adolescents with Down syndrome. In: MILLER, J. F.; LEAVITT, L. A.; LEDDY, M. (Ed.). Improving the Communication of People with Down Syndrome. Baltimore, MD: Paul H. Brookes Publishing. 1999. p. 41-60.

CHAPMAN, R. S. Language and communication in individuals with Down syndrome. In: Abbeduto, L. (Ed.). International Review of Research in Mental Retardation: Language and Communication, Academic Press, v. 27, p. 1-34, 2003.

CHAPMAN, R. S.; HESKETH, L. J. Behavioural phenotype of individuals with Down syndrome. Mental Retardation and Developmental Disability Research Reviews, v. 6, p. 84-95, 2000

CHAPMAN, R. S.; HESKETH, L. J. Language, cognition and short term memory in individuals with Down Syndrome. Down Syndrome Research and Practice, v. 7, n. 1, p. 1-7, 2001.

CUPPLES, L.; IACONO, T. Phonological awareness and oral reading skills in children with Down syndrome. Journal of Speech, Language and Hearing Research, v. 43, n. 3, p. 595-608, jun. 2000.

DANEMAN, M.; CARPENTER, P. A. Individual differences in working memory and reading. Journal of Verbal Learning and Verbal Behavior, v. 19, p. 450-466, 1980.

DODD, B. A comparison of the phonological systems of mental age matched, normal, severely subnormal and Down's syndrome children. Br. J. Disord. Commun, v. 11, p. 27-42, 1976.
FLETCHER, H.; BUCKLEY, S. Phonological awareness in children with Down syndrome. Down Syndrome Research and Practice, v. 8, n. 1, p. 11-18, mar. 2002. Disponível em: <http:// www.down-syndrome.org/reports/123/reports-123.pdf $>$. Acesso em: 09 dez. 2015.

FOWLER, A. E.; DOHERTY, J. B.; BOYNTON, L. The basis of reading skill in young adults with Down Syndrome. In: NABEL, L.; ROSENTHAL, D. (Ed.). Down syndrome: living and learning in the communit. New York: John Wiley \& Sons, 1995. p. 182-196.

FREITAS, G. C. M. Consciência fonológica: rimas e aliterações no português brasileiro. Letras de Hoje, Porto Alegre, v. 132, p. $155-170,2003$.

FREITAS, G. C. M. Sobre a consciência fonológica. In: LAMPRECHT; R.; BONILHA, G. F. G.; FREITAS, G. C. M.; MATZENAUER, C. L. B.; MEZZOMO, C. L.; OLIVEIRA, C. C.; RIBAS, L. P. Aquisição fonológica do português: perfil de desenvolvimento e subsídios para terapia. Porto Alegre: Artmed, 2004. 232 p.

GATHERCOLE, S.; PICKERING, S. J.; AMBRIDGE, B.; WEARING, H. The structure of working memory from 4 to 15 years of age. Dev. Psychol., v. 40, n. 2, p. 177-190, 2004.

GOSWAMI, U.; BRYANT, P. Phonological Skills and Learning to Read. Hillsdale: Lawrence Erlbaum, 1990. 188 p.

KARMILOFF-SMITH, A. From meta-processes to conscious access: Evidence from children's metalinguistic and repair data. Cognition, v. 23, p. 95-147, 1986.

KARMILOFF-SMITH, A. Beyond Modularity: a developmental perspective on cognitive science. Cambridge (MA): MIT, 1992. $234 \mathrm{p}$.

KARMILOFF-SMITH, A. Précis of Beyond modularity: A developmental perspective on cognitive science. Behavioral and brain sciences, v. 17, p. 693-745, 1994.

KARMILOFF-SMITH, A. Development itself is the key to understanding developmental disorders. Trends in Cognitive Sciences, v. 2, n. 10, p. 389-398, 1998.

KENNEDY, E. J.; FLYNN, M. C.Training phonological awareness skills in children with Down syndrome. Research in Developmental Disabilities, v. 24, p. 44-57, 2003.

KENNEDY E. J.; FLYNN M. C. Early phonological awareness and reading skills in children with Down syndrome. Down Syndrome Research and Practice, v. 8, n. 3, p. 100-109, 2003.

LORANDI, A. A consciência linguística e o modelo de Redescrição Representacional: como explicar a discrepância entre os processos de consciência em diferentes microdomínios? In: FERREIRA-GONÇALVES, G.; BRUM DE PAULA, M. R.; KESKE-SOARES, M. (Org.). Estudos em Aquisição Fonológica. Pelotas: Editora UFPel, 2011a. p. 205-217.

MAJOR, E. M.; BERNHARDT, B., Metaphonological skills of children with phonological disorders before and after phonological and metaphonological intervention. International Journal of Language and Communication Disorders, v. 33, p. 413-444, 1998.

MILLER, J. F.; LEDDY, M. G.; LEAVITT, L. A. Improving the Communication of People with Down Syndrome. Baltimore, MD: Paul H. Brookes Publishing, 1999. 304 p. 
MORAIS, J.; BERTELSON, P.; CARY, L., ALEGRIA, J. Literacy training and speech segmentation. Cognition, v. 24, p. 45-64, 1986.

ROBERTS, J. E.; PRICE, J.; MALKIN, C. Language and communication development in Down syndrome. Mental Retardation and Developmental Disabilities Research Reviews, v. 13, n. 1, p. 26-35, 2007.

ROSIN, M.; SWIFT, E.; BLESS, D. Communication profiles in adolescents with Down syndrome. J. Childhood Commun. Disord., v. 12, p. 49-64, 1988.

SCHWARTZMAN, J. S. (Org.). Síndrome de Down. São Paulo: Mackenzie: Memnon, 1999. 324 p.

SHALLICE, T. Fractionation of the supervisory system. In: STUSS, D. T.; KNIGHT, R. T. (Ed.). Principles of frontal lobe function. New York: Oxford University Press, 2002. p. 261-277.

STOEL-GAMMON, C. Phonological analysis of four Down's syndrome children. Appl. Psycholinguistics, v. 1, p. 31-48, 1980.
STRAY-GUNDERSEN, K. Babies with Down syndrome: A new parents guide. Rockville, MD: Woodbine House, 1986.

TUNMER, W. E.; HERRIMAN, M. L. The development of metalinguistic awareness: a conceptual overview. In: TUNMER, W. E.; PRATT, C.; HERRIMAN, M. L. (Ed.). Metalinguistic awareness in children: theory, research and implications. Berlin: Springer-Verlag, 1984. p. 12-35.

van BYSTERVELDT, A. K.; GILLON, G.; FOSTER-COHEN, $\mathrm{S}$. Integrated speech and phonological awareness intervention for pre-school children with Down syndrome. International Journal of Language \& Communication Disorders, v. 45, p. 320-335, 2010.

Recebido: 30/09/2017

Aprovado: 15/03/2018

Contato:

Maria Eugênia da Fontoura Porcellis <maria.fontoura@hotmail.com> 